\title{
The role of neutrophilic extracellular traps in oncogenesis
}

\author{
Mereke Maratkyzy $^{1}$, Aruna Kosybayeva ${ }^{2}$, Naylya Kabildina ${ }^{1}$, Anel Beisenayeva ${ }^{1}$ \\ ${ }^{\prime}$ Oncology and Radiodiagnosis Department, Karaganda \\ Medical University, Karaganda, Republic of Kazakhstan \\ ${ }^{2}$ No3 Department of Internal Medicine, Karaganda \\ Medical University, Karaganda, Republic of Kazakhstan

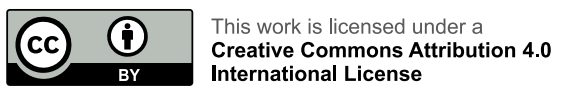

\section{Abstract} \\ Views on the role of extracellular neutrophilic traps in oncology vary \\ greatly. On the one hand, there is evidence of the anticarcinogenic properties \\ of neutrophil networks associated with the direct destruction of tumor cells \\ and stimulation of the immune system. Cytotoxicity towards tumor cells is \\ manifested by trap components (myeloperoxidase, proteinases and histones), \\ while DNA strands are considered as a kind of tool for capturing tumor cells and \\ limiting their further spread.
}

\section{Received: 2019-01-24}

Accepted: 2019-02-16

UDC: $616-006-008.853$

\section{J Clin Med Kaz 2019;1(51):16-20}

Corresponding Author: Mereke Maratkyzy, Oncology and Radiodiagnosis Department, Karaganda Medical University. Address: 40, Gogol Street, Karaganda, Republic of Kazakhstan. Tel.: +77001427530

Email: MaratkyzyM@kgmu.kz
Key words: extracellular neutrophilic traps, oncology, tumor

\section{ЖАСУШАДАН ТЫС НЕЙТРОФИЛЬДІ ТОРШАЛАРДЫН ОНКОГЕНЕЗДЕГІ РОЛІ}

Маратқызы М. ${ }^{1}$, Косыбаева А.Е. ${ }^{2}$, Кабилдина Н.А. ${ }^{1}$, Бейсенаева А.P. ${ }^{1}$

'Онкология және сәулелік диагностика кафедрасы, Қарағанды Медициналық Университеті, Қарағанды, Қазақстан Республикасы

${ }^{2} № 3$ ішкі аурулар кафедрасы, Қарағанды Медициналық Университеті, Қарағанды, Қазақстан Республикасы

\section{ТҰЖЫРЫМДАМА}

Жасушадан тыс нейтрофильді торшалардың онкологиядағы рөлі туралы пікірлер айтарлықтай өзгеше. Бір жағынан, нейтрофильді торшалардың ісік жасушаларын тікелей бұзуымен және иммундық жүйені ынталандырумен байланысты антиканцерогенді қасиеті туралы мәліметтер бар. Ісік жасушаларына бағытталған цитотоксикалық қасиетін нейтрофрильді торшалардың компоненттері (миопероксидаза, протеиназдар және гистондар) көрсетеді, ал ДНК тізбектері ісік жасушаларын ұстап, әрі қарай таралуын шектейтін құрал ретінде қарастырылады.

Негізгі сөздер: жасушадан тыс нейтрофильді торшалар, онкология, обыр

\section{РОЛЬ НЕЙТРОФИЛЬНЫХ ВНЕКЛЕТОЧНЫХ ЛОВУШЕК В ОНКОГЕНЕЗЕ}

Маратқызы М. ${ }^{1}$, Косыбаева А.Е. ${ }^{2}$, Кабилдина Н.А. ${ }^{1}$, Бейсенаева А.P. ${ }^{1}$

${ }^{1}$ Кафедра онкологии и лучевой диагностики, Медицинский Университет Караганды, Караганда, Республика Казахстан

${ }^{2}$ Кафедра внутренних болезни №3, Медицинский Университет Караганды, Караганда, Республика Казахстан

\section{РЕЗЮМЕ}

Представления о роли внеклеточных нейтрофильных ловушках при онкологии сильно варьируют. С одной стороны, есть данные об антиканцерогенных свойствах нейтрофильных сетей, связанных с прямым разрушением опухолевых клеток и стимуляцией иммунной системы. Цитотоксичность по отношению к опухолевым клеткам проявляют компоненты ловушек (миелопероксидаза, протеиназы и гистоны), тогда как нити ДНК рассматриваются как своего рода инструмент для захвата опухолевых клеток и ограничению их дальнейшего распространения.

Ключевые слова: внеклеточные нейтрофильные ловушки, онкология, рак 


\section{Введение}

Хорошо известно, что рак и иммунная система тесно связаны. Их взаимодействие определяет многие аспекты клинического проявления и прогрессирования рака. Нейтрофилы, как правило, выражают противовоспалительную активность и при определенных условиях убивают рассеянные раковые клетки, но согласно современным представлениям периферийное соотношение нейтрофилов крови к лимфоцитам указывает на плохой прогноз для пациентов со злокачественными новообразованиями, способствуя метастазированию [1-3].

Целью данного обзора является освещение роли нейтрофильных внеклеточных ловушек при онкологической патологии на основе использования современных научных данных.

Согласно классической концепции, нейтрофилы - это «профессиональные фагоциты», обеспечивающие реакции неспецифического врожденного иммунитета. Они являются преобладающим видом лейкоцитов в периферической крови людей и составляют 50-70\% от всех циркулирующих клеток этого типа [4-6].

Нейтрофилы осуществляет основную роль фагоцитоза, а так же выполняют в экстрацеллюлярном пространстве дегрануляцию цитотоксических энзимов. Они вырабатывают во внеклеточную среду сетчатые строения, которые состоят из нуклеиновых кислот и ферментов называемые внеклеточные нейтрофильные ловушки (НВЛ). Эти сети так же как и нейтрофилы уничтожают микроорганизмы $[7,8]$.

Многочисленные работы посвящены в этой проблеме, но на сегодняшний день нет четких данных об образовании нейтрофилами внеклеточных ловушек.

Взаимодействие организма с чужеродными веществами приводит к активизации нейтрофилов и они начинают выделять большое количество активных форм кислорода (АФК) путем активации of NADPH oxidase. В свою очередь АФК побуждают поток внутриклеточных перестроек, ведущих к образованию НВЛ. Деконденсация хроматина начинается с деградации линкерного гистона $\mathrm{H} 1$ с последующим разрушением нуклеосом. В результате происходит разрушение ядерной оболочки, затем плазматической мембраны, причем в этом процессе участвуют белки цитоскелета нейтрофилов. Деконденсированная молекула ДНК, к нитям которой прикреплены протеолитические белки гранул, гистоны, выбрасывается в межклеточное пространство или кровь, образуя трехмерную сеть. В этой сети застревают патогены, которые затем уничтожаются антимикробными белками. Литический механизм занимает 3-4 часа, и он приводит к клеточной смерти [9-11].

В последнее время описаны еще два пути образования НВЛ. Витальный быстрый путь (в течение 5-60 мин) или везикулярный механизм образования НВЛ, который является кислороднезависимым, при этом нейтрофилы на некоторое время сохраняют свою жизнеспособность $[12,13]$.

Между внешней и внутренней ядерной мембраной образуется пространство формированием везикул, содержащих хроматин. Окруженные ядерной мембраной везикулы перемещаются в межклеточное пространство и высвобождают хроматин за пределами клетки $[14,15]$.

Третий механизм образования НВЛ связанный с высвобождением митохондриальной ДНК, при этом жизнеспособность клетки на некоторое время сохраняется. Формирование митохондриальной НВЛ изучено недостаточно [13,16].

Наличие разнообразных клеточных популяций, циркулирующих в крови, проявляющих нейтрофильных ловушек и демонстрирующих иммуносупрессирующие или провоспалительные свойства, было зарегистрировано при системном воспалении, аутоиммунных болезнях и опухолевом процессе [17-19]. Существует две основные виды нейтрофилов: нейтрофилы низкой плотности и нейтрофилы нормальной плотности. Их получают при центрифугировании периферической крови. А так же, при применении такой методики, как лизис эритроцитов и сортинг полной лейкоцитарной взвеси, получают еще одну форму «нефракционированных» нейтрофилов $[20,21]$. Они демонстрируют увеличенную способность вырабатывать и экскретировать провоспалительные молекулы и аутоантигены, такие, как нейтрофильные экстрацеллюлярные «ловушки» [22].

В эксперименте с мышами, не имеющих раковых клеток в организме, преобладало нейтрофилы с высокой плотностью, a нейтрофилы с низкой плотностью доминировало у животных с тумором. Соответственно у этих нейтрофилов снижался цитотоксическая функция и уменьшалось экспрессия разных хемокинов, таким образом доказывало ухудшение противовоспалительной активности. На основе этой работы исследователи предположили, что при опухолях в крови бывают три популяции нейтрофилов с разными функциями: нормальные с высокой плотностью, крупные зрелые с низкой плотностью, незрелые с низкой плотностью. Нейтрофилы на фоне влияния хемокинов и цитокинов в окружении опухоли показывают различный туморогенный роль: с высокой плотностью обладают антиканцерогенный, а низкой плотностью, наоборот, распространяют опухоль $[23,24]$.

Представления о роли НВЛ при онкологии сильно варьируют. С одной стороны, есть данные об антиканцерогенных свойствах НВЛ, связанных с прямым разрушением опухолевых клеток и стимуляцией иммунной системы. Цитотоксичность по отношению к опухолевым клеткам проявляют компоненты НВЛ (миелопероксидаза, протеиназы и гистоны), тогда как нити ДНК рассматриваются как своего рода инструмент для захвата опухолевых клеток и ограничению их дальнейшего распространения $[25,26]$. С другой стороны, НВЛ могут способствовать миграции и иммунному избеганию опухолевых клеток. Высказано предположение о возможной роли НВЛ как прогностического биомаркера течения неопластического процесса $[3,19]$.

До настоящего времени роль НВЛ в канцерогенезе освещена в значительно меньшей степени и отсутствует однозначное мнение по использованию клеточных элементов естественного иммунитета. К примеру, ученые из Шанхайского Онкологического Центра Wei Jin и соавт продемонстрировали в своем исследовании, что при раке поджелудочной железы у пациентов без инфильтрационных нейтрофильных внеклеточных ловушек опухоли значительно выше пятилетняя выживаемость и безрецидивный период, чем у пациентов с опухолью 
инфильтрации нейтрофилов [27]. Тем самым они доказали, что нейтрофилы, инфильтрирующие опухоль, могут прогнозировать рецидив и выживаемость пациентов раком поджелудочной железы.

Man Nie и его коллеги с Центра Рака Университета Сунь Ят-Сена из Китая, изучая НВЛ крови и опухоли у больных с В-клеточной лимфомой обнаружили, что стимуляция НВЛ может увеличить экспрессию TLR9 рецепторов в опухолевых клетках. Поскольку НВЛ состоят из ДНК, полученной из нейтрофилов, декорированной белками, а TLR9 является важным ДНК-датчиком, имеет смысл, что TLR9 может организовывать прогрессирование опухоли в ответ на НВЛ, показывая противоположный биологический эффект [28].

Раковые клетки из первичной опухоли могут распространяться в другие ткани, оставаясь бездействующими и клинически не обнаруживаемыми в течение многих лет. Мало что известно о сигналах, которые заставляют эти спящие клетки пробуждаться, возобновлять пролиферацию и развиваться в метастазы. Изучая модели мышей, Albrengues J. и другие обнаружили, что устойчивое воспаление легких и сопровождающее образование НВЛ могут превращать бездействующие раковые клетки в агрессивные метастазы в легких. Пробуждение этих клеток было связано с НВЛ опосредованным ремоделированием внеклеточного матрикса и могло быть предотвращено антителом против модифицированной версии матричного белка $[29,30]$.

Ученые из Филадельфии, изучая НВЛ при раке легкого, проводя многочисленные экспериментальные исследования на мышах показали, что существует 2 группы нейтрофилов, так называемые - N1 и N2. В начальных стадиях рака НВЛ характеризует цитотоксичность по отношению к раковым клеткам. Ловушки вырабатывали более высокие уровни фактора некроза опухоли альфа. C другой стороны, НВЛ на поздних стадиях развития этих опухолей уже демонстрировали проопухолевый эффект [31,32]. Следовательно, можно предположить, что нейтрофилы, проникая в раковые клетки, в дальнейшем способствуют распространению канцероматоза. Таким образом, НВЛ полученные от мышей с растущим раком, могут иметь как антиканцерогенный потенциал N1, а N2 - нейтрофилы имеющий протуморогенный потенциал, который способен стимулировать развитию канцера и подавлять противоопухолевые иммунные реакции, зависящие от микроокружения опухоли [33,34]. Таким образом они предполагают модифицирующее действие тумора на активность нейтрофилов, то есть конечный эффект при этом зависел от типа опухоли, место локализации и стадии ее развития.

В своей работе А.Б. Семенова показала, что при раке молочной железы нейтрофилы усиленно и за короткое время образуют экстрацеллюлярные сети ДНК в опухолях c дифференцировкой G3, чем G1. Нейтрофильные сети локально находясь рядом с тумором, обхватывая, устанавливая границу друг с другом, или наоборот, прилепляют опухолевые клетки. А так же автор доказал, что окруженная внеклеточными сетями ДНК, является одним из механизмов «уклонения» или экранирования раковых клеток от продуктивных антиканцерогенных механизмов иммунной системы [35,36].

Результат исследований, проведенных при раке слизистой оболочки полости рта, продемонстрировали, что структуры нейтрофильных ловушек могут способствовать миграции и иммунному выходу раковых клеток или представлять собой физический барьер между раковыми клетками и иммунокомпетентными клетками. Кроме того, чрезмерное образование НВЛ в непосредственной близости от стенок кровеносных сосудов может облегчить связывание опухолевых клеток с эндотелием и способствовать экстравазации и вовлечению в процесс метастазирования рака. Однако, в этой же работе доказано, что сети могут улучшить иммунную защиту, покрывая циркулирующие раковые клетки тромбоцитами [37].

У онкологических больных часто возникают гемостатические дефекты, которые могут усугубляться химиотерапией и в конечном итоге приводить к тромбоэмболическим осложнениям. Тромбоэмболические заболевания являются второй по частоте причиной смерти от рака [38,39]. Ученые Европейского Института Онкологии в Милане (Италия) провели исследование НВЛ при раке кишечника. Они показали, что спонтанный онкогенез кишечника коррелирует с накоплением нейтрофилов низкой плотности с проонкогенным N2фенотипом и формированием НВЛ. Повышенный уровень циркулирующего липополисахарида вызывает активацию рецептора С3а комплемента на нейтрофилах и активацию каскада комплемента. Это приводит к NETosis, индукции коагуляции и поляризации N2, что вызывает онкогенез, показывая новую связь между коагуляцией, нейтрофилией и активацией комплемента. В когорте пациентов с ранней стадией рака кишечника находили корреляцию между нейтрофилией и гиперкоагуляцией. Это исследование дало механистическое объяснение стимулирующим опухоль эффектам гиперкоагуляции, которые могут быть использованы в качестве нового биомаркера или в качестве терапевтической мишени [40].

В работах ученых из ближнего зарубежья в микропрепаратах и мазках- отпечатках карцином гортани обнаружено, что рядом с тумором в ответ на взаимодействие с клетками рака генерализованно и каскадами располагается экстрацеллюлярная ДНК в виде сетей, вероятно выделенная в комплекте с элементами гранул. Следовательно, можно предположить, что нельзя исключить неспецифический характер механизма формирования внеклеточных сетей ДНК в ответ на воздействие тумора [41].

В работах отечественных исследователей по НВЛ при раке шейки матки, показано чувствительность нейтрофилов к химиотерапии и лучевой терапии.

Способность формировать сети значительно различалась после лучевой терапии. Добавление химиотерапевтических препаратов в лучевую терапию не увеличило процент НВЛ в крови пациентов данным заболеванием, но стимулировало появление базофильных внеклеточных ловушек [42].

Нейтрофильные клетки, являясь обязательным компонентом в микроокружении тумора, играют значительную роль в онкогенезе. Учитывая вышеизложенное, акцентируется двойной антиканцерогенный и протуморальный характер нейтрофилов и предполагается, что нейтрофилы могут быть использованы для усиления различных антиканцерогенных реакций в организме. Сведений о стадии онкогенеза, на которой противоопухолевая активность нейтрофильных внеклеточных ловушек сменяется на проопухолевую, и какие причины или факторы (степень морфологической 
дифференцировки, анатомический тип роста опухоли) способствуют этому процессу, в доступной литературе найти не удалось. Не освещены вопросы воздействия разных видов противоопухолевой терапии на поведение НВЛ, что требует дальнейшего углубленного исследования.

\section{Благодарность}

Авторы выражают благодарность доктору медицинских наук, профессору кафедры онкологии и лучевой диагности медицинского университета Караганды Сирота В.Б и доктору биологических наук, профессору кафедры биологической химии Муравлёвой Л.Е. за содействие в научно исследовательской работе.

Disclosures: There is no conflict of interest for all authors.

\section{Литература}

1. Lisjanyj NI, Lysjanyj AA. Neutrophils and Oncogenesis [in Russian]. Klinicheskaja onkologija. 2018;1(29):40-45.

2. Dolgushin II, Shishkova JuS, Semenova AB, Kazachkov EL, Vazhenin AV, Shamanova AV i dr. A look at the role of neutrophil extracellular DNA as a component of the tumor microenvironment in carcinogenesis processes [in Russian]. Ural'skij medicinskij zhurnal. 2014;2(116):19-22.

3. Danilova AB, Baldueva IA. Neutrophils as a component of the tumor microenvironment [in Russian]. Voprosy onkologii. 2016;62(1):3644

4. Fridlender ZG, Albelda SM. Tumor-associated neutrophils: friend or foe? Carcinogenesis. 2012; 33 (5):949-955. https://doi.org/10.1093/ carcin/bgs 123

5. Haitov RM, Ignat'eva GA, Sidorovich IG. Immune system and pathology [in Russian]. Immunologija. Norma i patologija. 2010 ; 215 $-240$

6. Jarilin AA. Neutrophils [in Russian]. Immunologija. 2010; 52 - 57.

7. Li P, Li M, Lindberg MR, Kennett MJ, Xiong N, Wang Y. PAD4 is essential for antibacterial innate immunity mediated by neutrophil extracellular traps. J. Exp. Med. 2010; 207:1853-62. https://doi.org/10.1084/jem.20100239

8. Mócsai A. Diverse novel functions of neutrophils in immunity, inflammation, and beyond. $J$ Exp Med. 2013; 210(7):1283-99. https:// doi.org/10.1084/jem.20122220

9. Fuchs TA, Abed U, Goosmann C. Novel cells death program leads to neutrophil extracelllular traps. J. Cell Biol. 2007; 176(2):231-241. https://doi.org/10.1083/jcb.200606027

10. Brinkmann V, Rechard U, Goosmann C. Neutrophil extracelllulartraps kill bacteria. Science 2004; 303:1532-1535. https://doi. org/10.1126/science.1092385

11. Korotina OL, Generalov II. Neutrophil extracellular traps: mechanisms of formation, function [in Russian]. Immunopatologija, allergologija, infektologija. 2012; 4:23-32

12. Yipp BG, Kubes P. NETosis: How vital is it? Blood. 2013; 122(16):2784-2794. https://doi.org/10.1182/blood-2013-04-457671

13. Andrjukov BG, Somova LM, Drobot EI, Matosova EB. Neutrophil granulocyte defensive strategies against pathogenic bacteria [in Russian]. Zdorov'e. Medicinskaja jekologija. Nauka. 2017; 1(68):4-18.

14. Pilsczek FH, Salina D, Poon KK, Fahey C, Yipp BG, Sibley CD. A novel mechanism of rapid nuclear neutrophil extracellular trap formation in response to Staphylococcus aureus. J Immunol. 2012; 185:7413-25. https://doi.org/10.4049/jimmunol.1000675

15. Yousefi S, Mihalache C, Kozlowski E, Schmid I, Simon, HU. Viable neutrophils release mitochondrial DNA to form neutrophil extracellular traps. Cell Death Differ. 2009; 16:1438-44. https://doi.org/10.1038/cdd.2009.96

16. Itagaki K, Kaczmarek E, Lee YT, Tang IT, Isal B, Adibnia Y et al. Mitochondrial DNA released by trauma induces neutrophil extracellular traps. PLoS One. 2015; 10(3):10-11. https://doi.org/10.1371/journal.pone.0120549

17. Savochkina AJu, Andreeva JuS, II. Dolgushin II. Methods of determination and the biological role of neutrophilic traps [in Russian]. Vestnik Ural'skoj akademicheskoj nauki. 2009; 2(1):335-336.

18. Vorob'eva NV, Pinegin BV. Neutrophil extracellular traps: mechanisms of formation, role in normal and pathological conditions (review) [in Russian]. Biohimija. 2014; 79(12):1580-1591

19. Berger-Achituv S, Brinkmann V, Abed UA, Kühn LI, Ben-Ezra J. Elhasid R, et al. A proposed role for neutrophil extracellular traps in cancer immunoediting. Frontiers Immunol. 2013; 4:48-49. https://doi.org/10.3389/fimmu.2013.00048

20. Carmona-Rivera C, Kaplan MJ. Low-density granulocytes: a distinct class of neutrophils in systemic autoimmunity. semin. Immunopathol. 2013; 35(4):455-463. https://doi.org/10.1007/s00281-013-0375-7

21. Dumitru CA, Moses K. Trellakis S. et al. neutrophils and granulocytic myeloid-derived suppressor cells: immunophenotyping, cell biology and clinical relevance in human oncology. Cancer Immunol. Immunother. 2012; 61(8):1155-1167. https://doi.org/10.1007/ s00262-012-1294-5

22. Pillay J, Tak T, Kamp VM, Koenderman L. Immune suppression by neutrophils and granulocytic myeloid-derived suppressor cells: similarities and differences. Cell Mol. Life sci. 2013; 70(20):3813-3827. https://doi.org/10.1007/s00018-013-1286-4

23. Sagiv JY, Michaeli J, Assi S. Phenotypic diversity and plasticity in circulating neutrophil subpopulations in cancer. Cell Reports. 2015; 10(4):562-573. https://doi.org/10.1016/j.celrep.2014.12.039

24. Yui S, Osawa Y, Ichisugi T, Morimoto-Kamata R. Neutrophil cathepsin G, but not elastase, induces aggregation of MCF-7 mammary carcinoma cells by a protease activity-dependent cell-oriented mechanism. Mediators Inflamm. 2014; 12. https://oi. org/10.1155/2014/971409.971409

25. Fomenko JuM, Zhumakaeva SS, Zhumakaeva AM, Sirota VB, Muravljova LE. Extracellular nucleic acids in oncological pathology [in Russian]. 2018; 2 
26. Semenova AB, Kazachkov EL., Dolgushin II, Vazhenin AV. Formation of extracellular DNA networks by neutrophilic granulocytes as an additional diagnostic criterion for the degree of malignancy of breast carcinomas [in Russian]. Ural'skij medicinskij zhurnal. 2016; 3:72-76.

27. Jin W, Xu HX, Zhang SR, Li H, Wang WQ, Gao HL, Wu CT, Xu JZ, Qi ZH, Li S, Ni QX, Liu L, Yu XJ Tumor-Infiltrating NETs Predict Postsurgical Survival in Patients with Pancreatic Ductal Adenocarcinoma. Send to Ann Surg Oncol. 2019; 26(2):635-643. https://oi. org/10.1245/s10434-018-6941-4

28. Nie M, Yang L, Bi X, Wang Y, Sun P, Yang H, Liu P, Li Z, Xia Y, Jiang W. Neutrophil extracellular traps induced by IL-8 promote diffuse large B cell lymphoma progression via the TLR9 signaling. Clin Cancer Res. 2018; 1226. https://doi.org/10.1158/1078-0432. CCR-18-1226

29. Albrengues J, Shields MA, Ng D, Park CG, Ambrico A, Poindexter ME et al Neutrophil extracellular traps produced during inflammation awaken dormant cancer cells in mice. Science. 2018; 361(6409). https://doi.org/10.1126/science.aao4227

30. Albrengues J, Wysocki RW, Maiorino L, Egeblad M. Re-cyclin' Cell-Cycle Components to Make NETs. Dev Cell. 2017; 43(4):379-380. https://doi.org/10.1016/j.devcel.2017.11.002

31. Fridlender ZG, Sun J, Kim S, Kapoor V, Cheng G, Ling L, Worthen GS, Albelda SM. Polarization of tumor-associated neutrophil phenotype by TGF-beta: «N1» versus «N2» TAN. Cancer Cell. 2009; 16:183-194. https://doi.org/10.1016/j.ccr.2009.06.017

32. Shaul ME, Levy L, Sun J, Mishalian I, Singhal S, Kapoor V. et al Tumor-associated neutrophils display a distinct N1 profile following TGF $\beta$ modulation: A transcriptomics analysis of pro- vs. antitumor TANs. Oncoimmunology. 2016; 13;5(11):e1232221. https://doi.org $/ 10.1080 / 2162402 X .2016 .1232221$

33. Homa-Mlak I, Majdan A, Mlak R, Małecka-Massalska T. Metastatic potential of NET in neoplastic disease. Postepy Hig Med Dosw.. 2016; 31;70(0):887-95.

34. Kobayashi Y. Neutrophil biology: an update. EXCLI J. 2015; 10(14):220-227. https://doi.org/10.17179/excli2015-102

35. Semenova AB, Shamanova AJu. The microenvironment of invasive carcinomas of the breast of «non-specific» and «specific» types, taking into account the malignancy of tumors (literature review) [in Russian]. Ural'skij medicinskij zhurnal. 2014; 8:23-28.

36. Semenova AB, Shamanova AJu, Shishkova JuS, Dolgushin II, Kazachkov EL, Vazhenin AV. The formation of autologous neutrophils extracellular DNA networks when meeting with tumor cells of breast carcinoma, depending on the degree of malignancy and tumor receptor status [in Russian]. Ural'skij medicinskij zhurnal. 2014; 8:29-32

37. Garley M, Dziemiańczyk-Pakieła D, Grubczak K, Surażyński A, Dąbrowska D, Ratajczak-Wrona W. et al Differences and similarities in the phenomenon of NETs formation in oral inflammation and in oral squamous cell carcinoma. J Cancer. 2018; 9(11):1958-1965. https://doi.org/10.7150/jca.24238

38. 38. Guglietta S, Chiavelli A, Zagato E, Krieg C, Gandini S, Ravenda PS et al Coagulation induced by C3aR-dependent NETosis drives protumorigenic neutrophils during small intestinal tumorigenesis. Nat Commun. 2016; 7:11037. https://doi.org/10.1038/ncomms11037

39. Elyamany G, Alzahrani AM, Bukhary E. Cancer-associated thrombosis: an overview. Clin Med Insights Oncol. 2014 ; 8:129-37. https://doi.org/10.4137/CMO.S18991

40. Mansour A, Ismael Y, Abunasser M, Hammode E, Turfa R, Abdel-Razeq H. The application of clinical variables and models tocpredict pulmonary embolism in cancer patients: a comprehensive single cancer center experience. Patient Prefer Adherence. 2013; 7:1111-6. https://doi.org/10.2147/PPA.S46372

41. Dolgushin I.I., Semenova A.B., Shishkova Ju.S., Kazachkov E.L., Vazhenin A.V., Shamanova A.Ju. Structural features of the formation of extracellular DNA networks by neutrophilic granulocytes when meeting with laryngeal carcinoma tumor cells [in Russian]. Ural'skij medicinskij zhurnal. 2015; 9:119-122

42. Fomenko Y., Kolesnikova Y., Beynikova I., Muravlyova L, Sirota V, Bakirova R. Influence of Combined Therapy on Generation of Neutrophil Extracellular Traps in Patients with Cervical Cancer. Open Access Maced J Med Sci. 2018; 6(11):2097-2100. https://doi. org/10.3889/oamjms.2018.483

How to cite this article: Mereke Maratkyzy, Aruna Kosybayeva, Naylya Kabildina, Anel Beisenayeva The role of neutrophilic extracellular traps in oncogenesis [in Russian]. J Clin Med Kaz. 2019; 1(51):16-20 